\title{
The 80th Birthday of Brian Josephson
}

\author{
John Rowell ${ }^{1}$
}

Published online: 27 November 2020

(C) Springer Science+Business Media, LLC, part of Springer Nature 2020

Dear Brian,

Congratulations on your 80th birthday.

Rumors of your proposals of "possible new effects" began to circulate at Bell Labs during the summer of 1962 and became more specific with the return of Phil Anderson from his year at Cambridge. They were not met with universal acceptance, especially by theorists! I was not able to attend the conference in London that summer, when you and John Bardeen exchanged your differing viewpoints on the reality of pair tunneling. Instead, my wife and I visited most of the National Parks from Vancouver to Arizona.

My interest in tunneling at Bell was due to the availability in the department of equipment that generated plots of the slope of current-voltage characteristics. It had been built by Don Thomas, Alan Chynoweth, and Ralph Logan for their studies of semiconductor diodes. The invention of the lock-in amplifier a few years later made such plots much easier to obtain.

Following the fabrication processes described by Ivar Giaever, I began to make $\mathrm{Al} / \mathrm{AlOx} / \mathrm{Pb}$ junctions in 1962. On January 3 of 1963, I decided to measure one such junction in the only cryostat at Bell that reached well below $1 \mathrm{~K}$. It was being used by Ted Geballe, Bernd Matthias, and Ernie Corenzwit in their search for new superconductors. Even at close to $0.3 \mathrm{~K}$, we saw

John Rowell

johnmrowell@gmail.com

1 Bell Telephone Laboratories, Murray Hill, New Jersey, USA nothing unusual in the $\mathrm{I}-\mathrm{V}$ characteristic. In hindsight, the junction resistance was too high, and the noise in that laboratory was large. Phil was surprised that we had not seen a supercurrent but then proposed the notion of a coupling energy which had to be large, implying that we needed junctions with lower resistances. Aluminum oxidizes so rapidly in laboratory air that the required short exposure of the film was difficult to achieve by venting a conventional evaporator.

During 1962, I had made a few junctions using oxidized tin as the base film, but their resistances were not reproducible. However, tin was an obvious choice, as its $\mathrm{Tc}$ of $3.7 \mathrm{~K}$ meant that a junction of $\mathrm{Sn} / \mathrm{SnOx} / \mathrm{Pb}$ would be fully superconducting well above $1 \mathrm{~K}$, which was the limit of my cryostat at the time.

On January 21, 1963, Len Kopf, my TA (Technical Assistant), assembled the apparatus sketched on page 37 of my laboratory notebook. It allowed oxidation of the tin film in dry oxygen at a certain temperature. The events of the day are then described in some detail (Making notebook entries each day was strongly encouraged at Bell, in case something "patentable" was achieved). The first junctions Len made were all good and had the hoped for low resistances. 


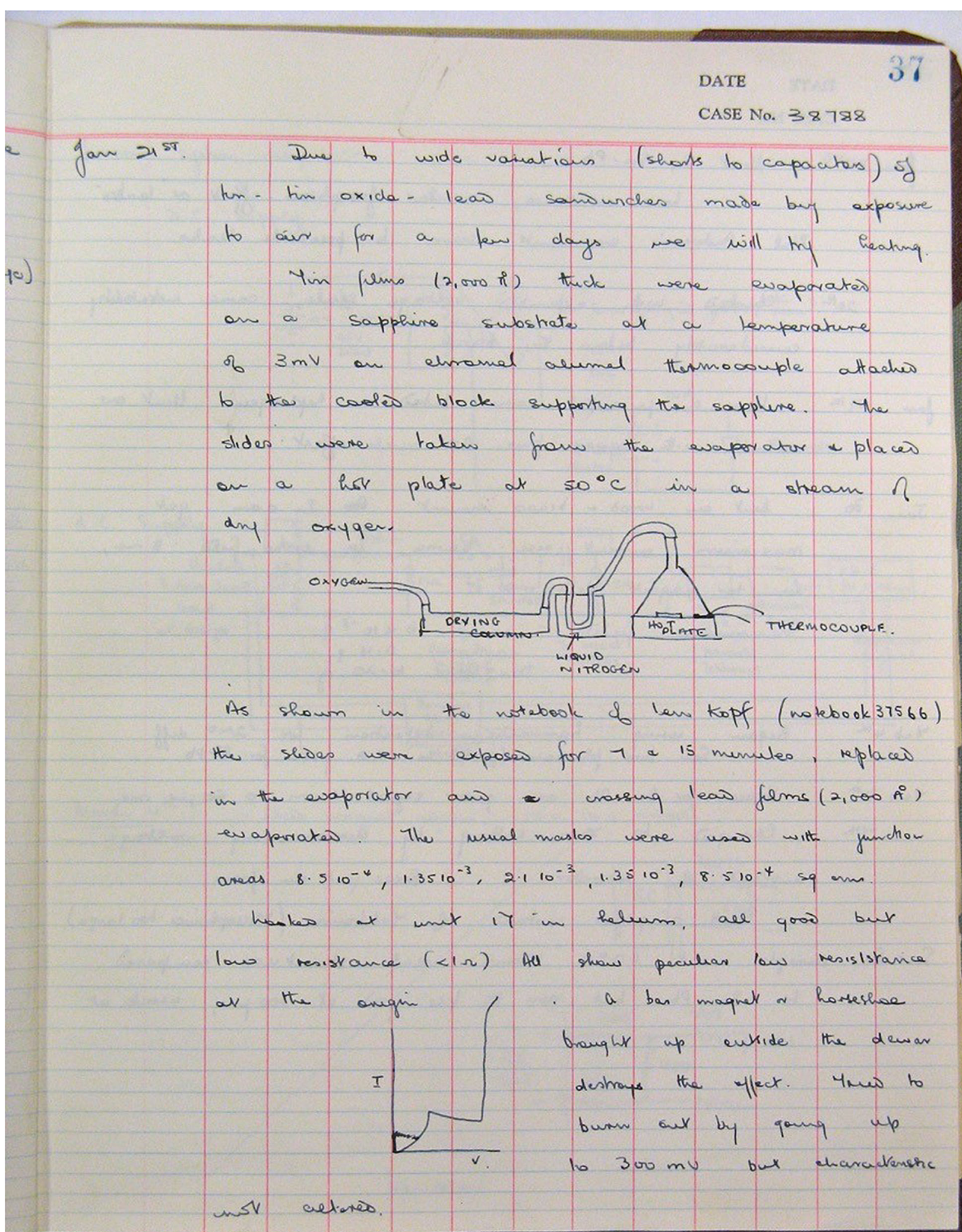


I observed a "peculiar low resistance at the origin." Your prediction of "novel" had become "peculiar." I observed that the small current was destroyed by moving a bar magnet near to the dewar; I even used a horseshoe magnet as well. I must have had both magnets nearby in the lab! I went down to Phil's office to tell him of these results, and he returned with me to the lab, took the bar magnet, and moved away towards the door, maybe 10 or $15 \mathrm{ft}$. The junction still showed that it was strongly affected by changes in the magnetic field.

I made the first measurement of the current versus magnetic field by sliding the bar magnet along the lower shelf of the lab bench, moving it closer to the dewar. The current was displayed on an X-Y recorder, and Ic $(\mathrm{H})$ was plotted on the recorder paper. I have often regretted that no copy was made of that sheet, and, unlike our notebooks, the recorder sheets were not stored indefinitely. As far as I know, all the Bell Labs notebooks are still kept in a warehouse in New Jersey.

The final sentence of page 37 describes a test I often used on junctions of questionable quality. If, for example, the junction had a small metallic filament through the oxide, it would have been destroyed by the large currents.

Another regret is that this plot of $\operatorname{Ic}(\mathrm{H})$ was not included in our first publication, and I believe it would have been more convincing than the "Probable observation" was. I remember that Phil debated with himself about the use of "Probable," maybe he thought your
"Possible" should be followed by "Probable." I also assume that a figure described as "The current near zero voltage in a $\mathrm{Sn} / \mathrm{SnOx} / \mathrm{Pb}$ tunnel junction versus the position of a magnet on the lab bench shelf" would not have been accepted by PRL, and probably not by my line of management at Bell either.

It was June 6 , well over 4 months later, before I had a solenoid made and calibrated, which was mounted in the liquid nitrogen around the junctions in the helium dewar. You might wonder why it took so long; my only explanation is that, for me, tunneling spectroscopy was always a major distraction. Instead of junctions with tin, by then we were routinely making them with lead, so $\mathrm{Pb} / \mathrm{PbOx} / \mathrm{Pb}$. They were fabricated in much the same way as the earlier tin junctions were. The description from my notebook of June 6 comments that the currents were so small at the minima of the diffraction pattern that I could only plot them using a logarithmic scale. At the superconductivity conference held that summer in Colgate NY, I remember that Brian Pippard pointed out that the oxide barrier across the junction must have been exceptionally uniform. That conference seemed to me to mark the end of any questions about the reality of your "Josephson Effects," as they had become known.

For myself, and for many others, let me thank you for all the years of employment we enjoyed in our studies of the science and applications of your Effects.

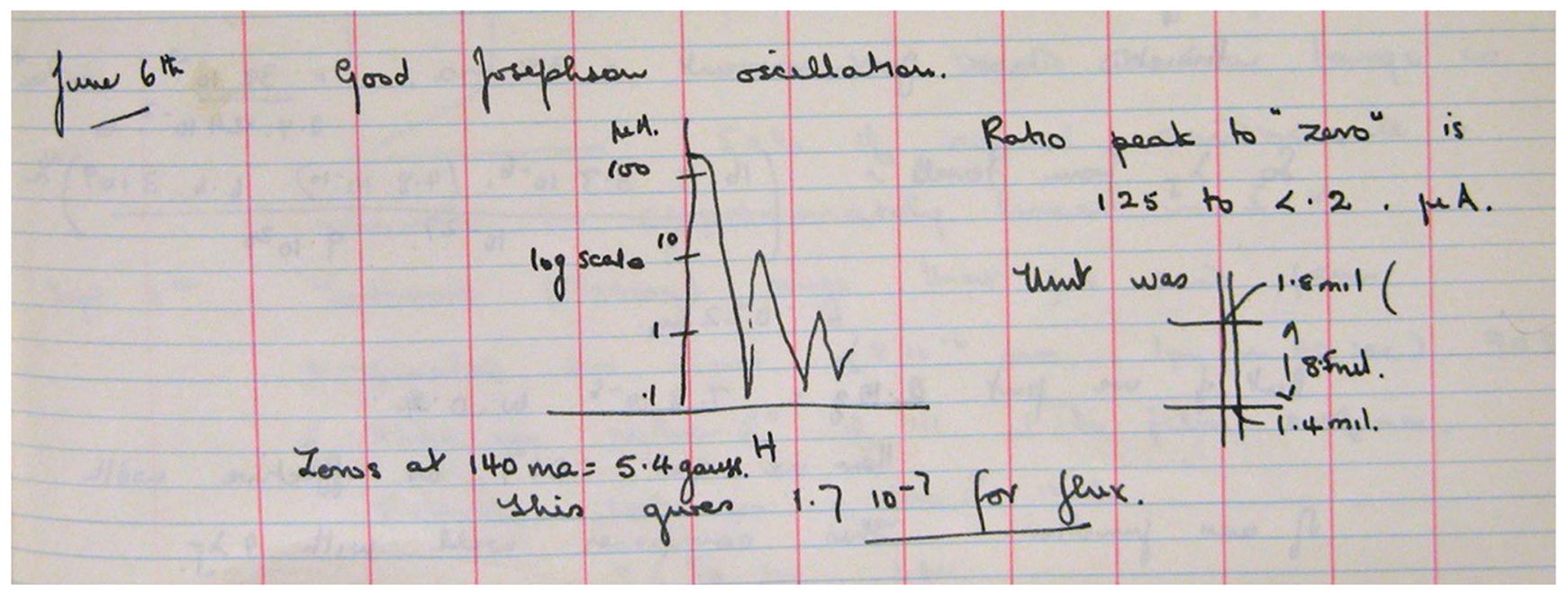

Very best wishes, John

Publisher's note Springer Nature remains neutral with regard to jurisdictional claims in published maps and institutional affiliations. 